\title{
Real-World Satisfaction with Secukinumab in Clearing the Skin of Patients with Plaque Psoriasis through 24 Months of Follow-Up: Results from US Dermatology Electronic Medical Records
}

\author{
April W. Armstrong - Dhaval Patil - Eugenia Levi · Catherine B. McGuiness • \\ Xin Wang · Yi Wang · Chi-Chang Chen · Elizabeth Nguyen • \\ Paul S. Yamauchi
}

Received: July 6, 2021 / Accepted: August 18, 2021 / Published online: August 28, 2021

(C) The Author(s) 2021

\section{ABSTRACT}

Introduction: Information on the long-term treatment satisfaction with secukinumab for patients with plaque psoriasis in real-world settings is limited. The objective of this study was to describe real-world treatment satisfaction in patients with plaque psoriasis who initiated secukinumab using data from an electronic medical records-based dermatology database.

Methods: Patients aged $\geq 18$ years with plaque psoriasis in Modernizing Medicine Data Services' affiliate's database who received secukinumab 3/1/2018-1/21/2020 were included. Satisfaction with the treatment's effectiveness in clearing the skin of psoriasis was evaluated

Supplementary Information The online version contains supplementary material available at https:// doi.org/10.1007/s13555-021-00599-5.

A. W. Armstrong

Keck School of Medicine of University of Southern

California, Los Angeles, CA, USA

D. Patil · E. Levi · E. Nguyen

Novartis Pharmaceuticals Corporation,

East Hanover, NJ, USA

C. B. McGuiness · X. Wang · Y. Wang · C.-C. Chen

IQVIA, Plymouth Meeting, PA, USA

P. S. Yamauchi $(\bowtie)$

David Geffen School of Medicine at UCLA,

Los Angeles, CA, USA

e-mail: paulyamauchi@yahoo.com using a 5-point Likert scale during the 12-month baseline period and at 6-, 12-, 18-, and 24-month postindex visits for the overall population and at 6-, 12-, and 18-month postindex visits for subgroups stratified by prior biologic and systemic therapy use. Additionally, satisfaction levels were assessed among patients who were unsatisfied with treatment at baseline.

Results: Overall, $82.3 \%$ agreed that secukinumab was effective in clearing their skin at 6 months, which was maintained through 12 (81.7\%), 18 (83.3\%), and 24 months (81.4\%). Similar results were observed in biologic-experienced/naive and systemic-experienced/naive patients. Overall mean (SD) treatment satisfaction improved from 2.49 (1.36) at baseline to 1.77 (1.06) at 6 months, with similar improvements in satisfaction scores reported at each follow-up period up through 24 months. Of the patients who were not satisfied at baseline, $77.9 \%$ reported being satisfied with their treatment at 6 months, which continued through 12 (74.4\%), 18 (82.8\%), and 24 months (71.4\%). Patients receiving secukinumab experienced meaningful changes in percent affected body surface area and Physician Global Assessment scores that were sustained through 24 months, regardless of prior treatment experience.

Conclusions: These real-world findings highlight the high level of sustained satisfaction with secukinumab treatment for improving and maintaining skin clearance in patients with 
moderate-to-severe disease, regardless of prior treatment experience.

Keywords: Plaque psoriasis; Treatment satisfaction; Secukinumab; Dermatology electronic medical records

\section{Key Summary Points}

Secukinumab is the first interleukin 17A inhibitor approved for the treatment of psoriasis and has demonstrated longlasting efficacy and safety in randomized controlled trials

However, limited data exist on the extent to which secukinumab increases patient satisfaction in a real-world setting

This work demonstrates the sustained satisfaction with secukinumab treatment through 24 months for improving and maintaining skin clearance in patients with moderate-to-severe disease, regardless of prior treatment experience or level of satisfaction at baseline

In real-world clinical settings, secukinumab can help provide a treatment that brings satisfaction to a high percentage of patients with plaque psoriasis

\section{INTRODUCTION}

Psoriasis is a chronic, systemic, immune-mediated disease of the skin that affects $>7.4$ million people in the USA, with an estimated prevalence of $2-4 \%$ [1]. The most common form of psoriasis is plaque psoriasis, affecting $80-90 \%$ of patients, which manifests as patches of raised, reddish skin covered with a silvery-white scale [2]. Studies assessing the burden of illness have shown that moderate-to-severe psoriasis is associated with a variety of comorbidities (e.g., psoriatic arthritis, hypertension, hyperlipidemia, cardiovascular disease, malignancy, obesity, depression, and anxiety), [3, 4] shortened life expectancy, [5] diminished health-related quality of life, [6] increased healthcare costs, [7], and lost productivity [8].

The American Academy of Dermatology guidelines recommend biologic therapies as among the first-line agents for treatment of patients with moderate-to-severe psoriasis [9]. Secukinumab is the first US Food and Drug Administration-approved interleukin 17A inhibitor (approval date: January 2015) and has shown long-lasting efficacy and safety in the treatment of the complete spectrum of psoriasis manifestations, including nail, scalp, and palmoplantar psoriasis as well as psoriatic arthritis [10-15]. Furthermore, secukinumab has demonstrated sustained skin clearance and improved quality of life through 5 years in patients with moderate-to-severe psoriasis [16].

Compared with those enrolled in clinical trials, a larger proportion of secukinumab-treated patients with psoriasis in US clinical practice are biologic experienced, and nearly half have concurrent psoriatic arthritis [17-19]. However, information on treatment satisfaction with secukinumab in US-based, real-world settings is insufficient. Real-world data are important because they capture patients with heterogeneous presentations of psoriasis and multiple comorbidities who may not be represented in clinical trials. The aim of this study was to describe real-world treatment satisfaction in patients with plaque psoriasis who initiated secukinumab in clinical practice.

\section{METHODS}

\section{Study Design and Patient Population}

All clinical data were obtained from the Modernizing Medicine Data Services' (MMDS) affiliate's dermatology electronic medical records (EMRs) system called Electronic Medical Assistant (EMA). EMA delivers structured real-world data from $>9000$ dermatology providers in the USA and has captured data from $>900,000$ unique patients with psoriasis.

Eligible patients in EMA had a diagnosis of plaque psoriasis during the study period of 1 
March 2017 to 31 July 2020, had $\geq 1$ prescription order for secukinumab within the index period of 1 March 2018 to 31 January 2020, and were aged $\geq 18$ years at the time of secukinumab initiation (index date) (Fig. 1). Patients had $\geq 1$ clinical encounter for any reason during the 12-month preindex (baseline) period and $\geq 1$ clinical encounter for any reason within the first and second 6 months following secukinumab initiation. Data from EMA were deidentified in compliance with Health Insurance Portability and Accountability Act regulations and were made available to all authors. This study was exempt from institutional review board review, as it did not involve the collection, use, or transmittal of individually identifiable data. Patients were stratified two ways based on prior biologic (adalimumab, certolizumab pegol, etanercept, infliximab, golimumab, ustekinumab, ixekizumab, brodalumab, abatacept, or guselkumab) and systemic medication [biologics or nonbiologic oral and injectable systemic agents (methotrexate, corticosteroids, acitretin, or apremilast)] use in the baseline period, resulting in four cohorts: biologic-naive, biologic-experienced, systemic-naive, and systemicexperienced.

\section{Study Variables and Data Analysis}

Baseline demographics (age, sex, race, US region), treatment history, and clinical characteristics [comorbidities, psoriasis subtype, affected BSA, Physician Global Assessment (PGA) score] were assessed by dermatology providers during the 12-month baseline period. Mean (SD) and categorical treatment satisfaction scores were evaluated during the 12-month baseline period and at 6-, 12-, 18-, and 24-month postindex visits (window, \pm 1 month) based on responses to the following statement: "I believe this treatment is effective in clearing my skin of psoriasis" ( 1 = strongly agree, $2=$ somewhat agree, 3 = neither agree nor disagree, $4=$ somewhat disagree, $5=$ strongly disagree). Patients who did not at least "somewhat agree" (i.e., scores of 3,4 , or 5) were considered "unsatisfied" in this study. Median and categorical affected BSA $(<3 \%=$ mild, $\quad 3 \%-10 \%=$ moder ate, $>10 \%=$ severe) and 5-point PGA score $(0=$ clear, $1=$ minimal, $2=$ mild, $3=$ moderate, 4 = severe) were evaluated during the 12-month baseline period-on the index visit or the visit closest to the index date-and at 6-, 12-, 18-, and 24-month postindex visits to calculate

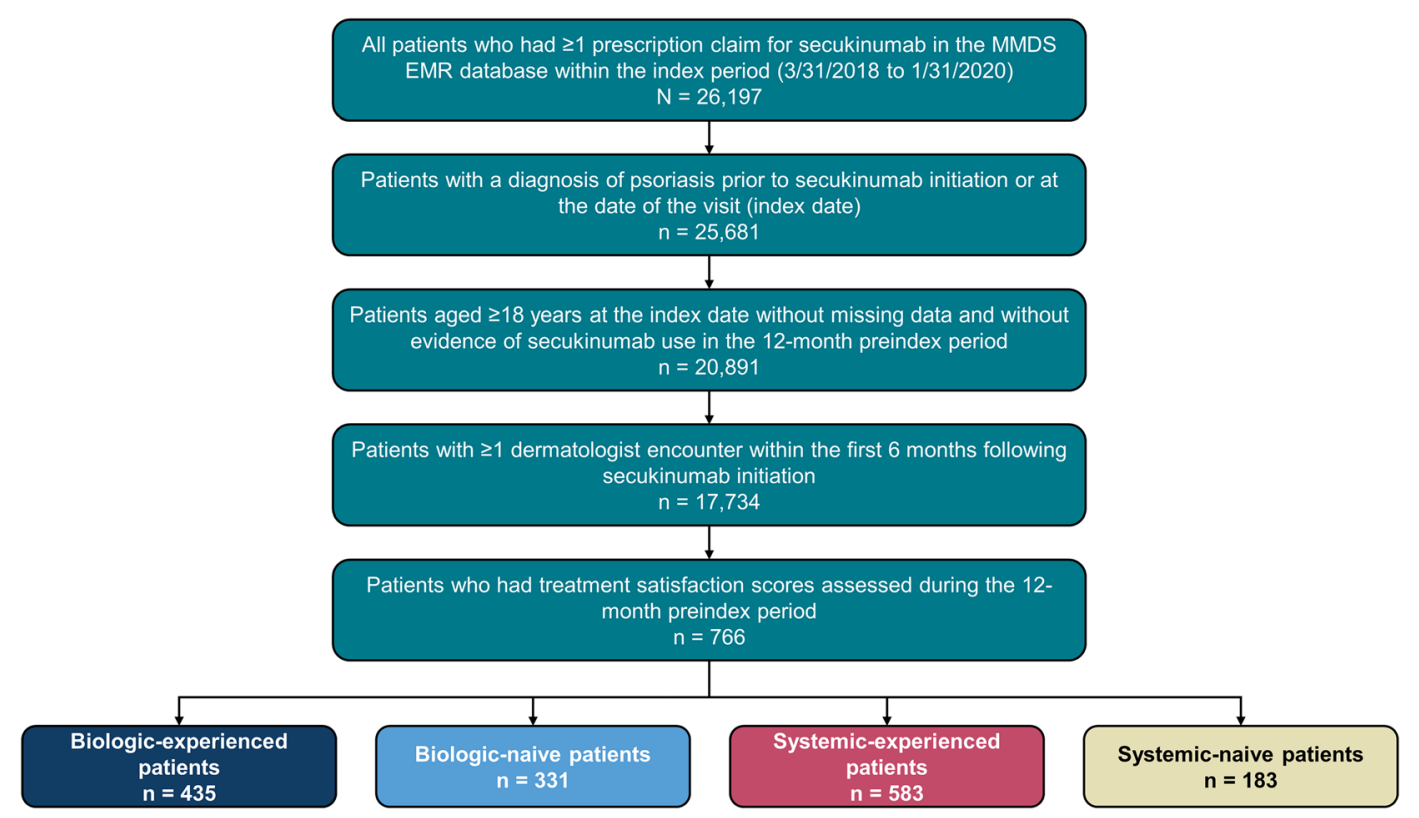

Fig. 1 Patient disposition. EMR, electronic medical record; MMDS, Modernizing Medicine Data Services 
Table 1 Baseline demographics, clinical characteristics, and treatment history of patients with psoriasis who initiated secukinumab and had treatment satisfaction scores at 6 months of follow-up

\begin{tabular}{|c|c|c|c|c|c|}
\hline Characteristic & $\begin{array}{l}\text { Overall } \\
(n=766)\end{array}$ & $\begin{array}{l}\text { Biologic } \\
\text { experienced } \\
(n=435)\end{array}$ & $\begin{array}{l}\text { Biologic } \\
\text { naive } \\
(n=331)\end{array}$ & $\begin{array}{l}\text { Systemic } \\
\text { experienced } \\
(n=583)\end{array}$ & $\begin{array}{l}\text { Systemic } \\
\text { naive } \\
(n=183)\end{array}$ \\
\hline Age, mean (SD), years & $51.8(14.5)$ & $51.6(14.2)$ & $52.1(14.9)$ & $51.7(14.4)$ & $52.3(14.7)$ \\
\hline Female, $n(\%)$ & $406(53.0)$ & $235(54.0)$ & $171(51.7)$ & $309(53.0)$ & $97(53.0)$ \\
\hline Weight, mean (SD), kg & $93.1(23.6)$ & $92.1(23.1)$ & $94.5(24.5)$ & $94.1(24.0)$ & $89.8(22.5)$ \\
\hline \multicolumn{6}{|l|}{ US region, $n(\%)$} \\
\hline South & $364(47.5)$ & $209(48.1)$ & $155(46.8)$ & $275(47.2)$ & $89(48.6)$ \\
\hline West & $160(20.9)$ & $90(20.7)$ & $70(21.2)$ & $119(20.4)$ & $41(22.4)$ \\
\hline Midwest & $161(21.0)$ & $86(19.8)$ & $75(22.7)$ & $123(21.1)$ & $38(20.8)$ \\
\hline Northeast & $81(10.6)$ & $50(11.5)$ & $31(9.4)$ & $66(11.3)$ & $15(8.2)$ \\
\hline \multicolumn{6}{|l|}{ Race, $n(\%)$} \\
\hline White & $437(57.1)$ & $251(57.7)$ & $186(56.2)$ & $335(57.5)$ & $102(55.7)$ \\
\hline Non-White/unknown & $329(43.0)$ & $184(42.3)$ & $145(43.8)$ & $249(42.5)$ & $81(44.3)$ \\
\hline \multicolumn{6}{|l|}{ Comorbidity, $n$ (\%) } \\
\hline Hypertension & $261(34.1)$ & $148(34.0)$ & $113(34.1)$ & $205(35.2)$ & $56(30.6)$ \\
\hline Psoriatic arthritis & $198(25.9)$ & $120(27.6)$ & $78(23.6)$ & $156(26.8)$ & $42(23.0)$ \\
\hline Diabetes & $138(18.0)$ & $74(17.0)$ & $64(19.3)$ & $103(17.7)$ & $35(19.1)$ \\
\hline Anxiety & $123(16.1)$ & $72(16.6)$ & $51(15.4)$ & $100(17.2)$ & $23(12.6)$ \\
\hline Depression & $110(14.4)$ & $56(12.9)$ & $54(16.3)$ & $85(14.6)$ & $25(13.7)$ \\
\hline Hyperlipidemia & $123(16.1)$ & $70(16.1)$ & $53(16.0)$ & $99(17.0)$ & $24(13.1)$ \\
\hline Malignancy & $91(11.9)$ & $60(13.8)$ & $31(9.4)$ & $74(12.7)$ & $17(9.3)$ \\
\hline Coronary heart disease & $21(2.7)$ & $10(2.3)$ & $11(3.3)$ & $16(2.7)$ & $5(2.7)$ \\
\hline Cerebrovascular disease $^{\mathrm{a}}$ & $15(2.0)$ & $8(1.8)$ & $7(2.1)$ & $11(2.0)$ & $4(2.2)$ \\
\hline PGA, mean $(S D)$ & $2.6(1.1)$ & $2.5(1.2)$ & $2.7(1.1)$ & $2.6(1.1)$ & $2.5(1.2)$ \\
\hline $\mathrm{BSA}$, mean $(\mathrm{SD})$ & $18.0(19.4)$ & $16.9(19.3)$ & $19.6(19.5)$ & $18.2(19.7)$ & $17.1(18.2)$ \\
\hline $\mathrm{PGA} \times \mathrm{BSA}$, mean $(\mathrm{SD})$ & $57.0(73.9)$ & $60.1(83.6)$ & $52.6(57.1)$ & $60.5(79.7)$ & $43.9(43.2)$ \\
\hline \multicolumn{6}{|c|}{ Prior biologic treatment during 12 months preceding secukinumab claim, $n(\%)$} \\
\hline Tumor necrosis factor inhibitor ${ }^{\mathrm{b}}$ & $211(27.5)$ & $211(61.2)$ & - & $211(61.2)$ & - \\
\hline IL-12/23 inhibitor & $103(13.4)$ & $103(29.9)$ & - & $103(29.9)$ & - \\
\hline IL-23 inhibitor (guselkumab and risankizumab) ${ }^{c}$ & $46(6.0)$ & $46(13.3)$ & - & $46(13.3)$ & - \\
\hline
\end{tabular}


Table 1 continued

\begin{tabular}{lccccc}
\hline Characteristic & $\begin{array}{l}\text { Overall } \\
(\boldsymbol{n}=766)\end{array}$ & $\begin{array}{l}\text { Biologic } \\
\text { experienced } \\
(\boldsymbol{n}=\mathbf{4 3 5})\end{array}$ & $\begin{array}{l}\text { Biologic } \\
\text { naive } \\
(\boldsymbol{n}=\mathbf{3 3 1})\end{array}$ & $\begin{array}{l}\text { Systemic } \\
\text { experienced } \\
(\boldsymbol{n}=\mathbf{5 8 3})\end{array}$ & $\begin{array}{l}\text { Systemic } \\
\text { naive } \\
(\boldsymbol{n}=\mathbf{1 8 3})\end{array}$ \\
\hline IL-17A inhibitor (brodalumab and ixekizumab) & $39(5.1)$ & $39(11.3)$ & - & $39(11.3)$ & - \\
Prior conventional systemic treatment during 12 months preceding the index secukinumab claim, $n(\%)$ & \\
Methotrexate & $86(11.2)$ & $40(9.2)$ & $46(13.9)$ & $86(14.8)$ & - \\
Acitretin & $15(2.0)$ & - & - & $15(2.6)$ & - \\
Apremilast & $96(12.5)$ & $40(9.2)$ & $56(16.9)$ & $96(16.5)$ & - \\
\hline
\end{tabular}

$B S A$ body surface area, $I L$ interleukin, $P G A$ Physician Global Assessment

${ }^{a}$ Cerebrovascular disease included hemorrhagic stroke and transient ischemic attack

b Tumor necrosis factor inhibitors included adalimumab, certolizumab pegol, etanercept, golimumab, and infliximab

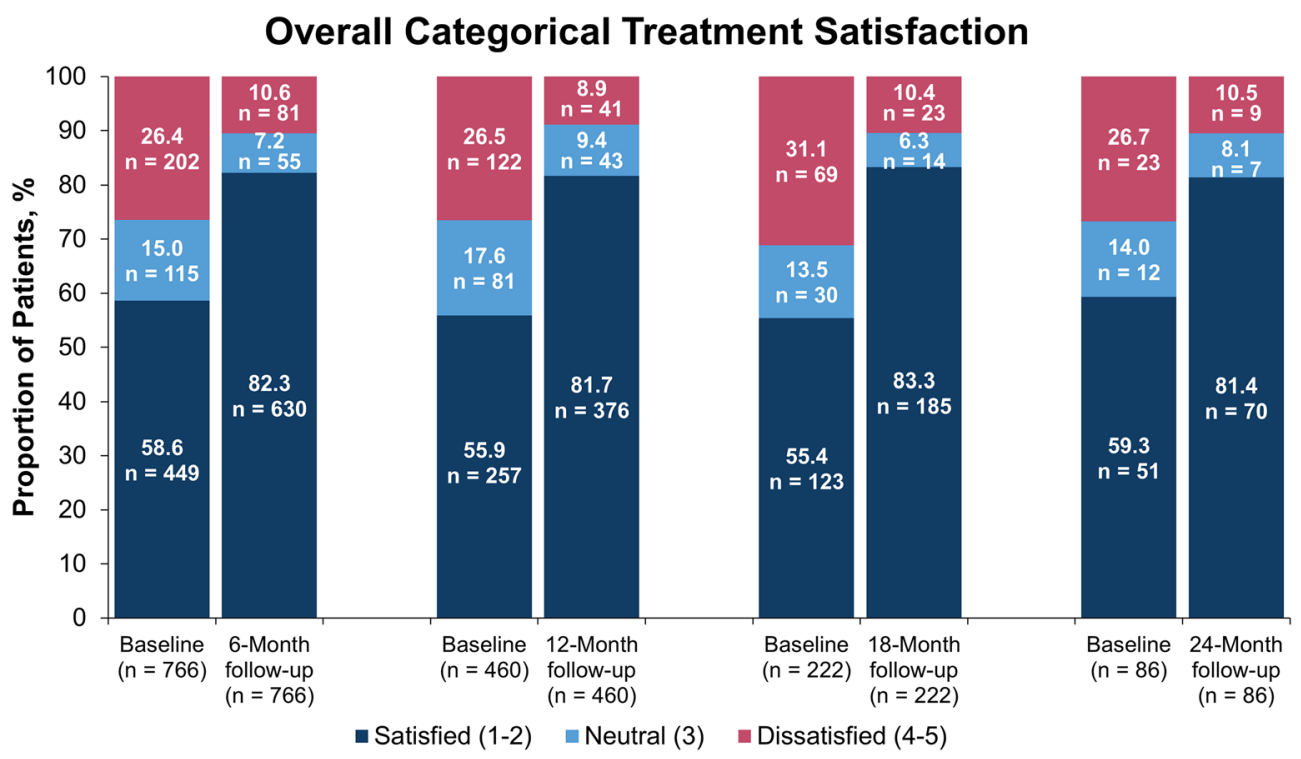

Fig. 2 Categorical change in treatment satisfaction ${ }^{\mathrm{a}}$ in all patients who initiated secukinumab who had baseline data and 6, 12, 18, and 24 months of follow-up ${ }^{\mathrm{b}}$. ${ }^{\mathrm{a}}$ Statement: "I believe this treatment is effective in clearing my skin of psoriasis" (1 = strongly agree, $2=$ somewhat agree, $3=$ neither agree nor disagree, $4=$ somewhat disagree,

PGA $\times$ BSA [20] as a valid, practical measure of psoriasis severity.

Categorical changes from baseline to 6-, 12-, $18-$, and 24-month postindex visits were calculated in patients with both baseline and
$5=$ strongly disagree). ${ }^{\mathrm{b}}$ Available effectiveness records for treatment satisfaction scores were reported based on the index visit or the visit closest to the index date. Baseline data were from enrolled patients who had 6-, 12-, 18-, and 24-month follow-up periods, respectively

postindex treatment satisfaction, BSA, and PGA $\times$ BSA data available in the overall population. Due to smaller sample sizes at longer follow-up, categorical changes in treatment satisfaction were only assessed through 

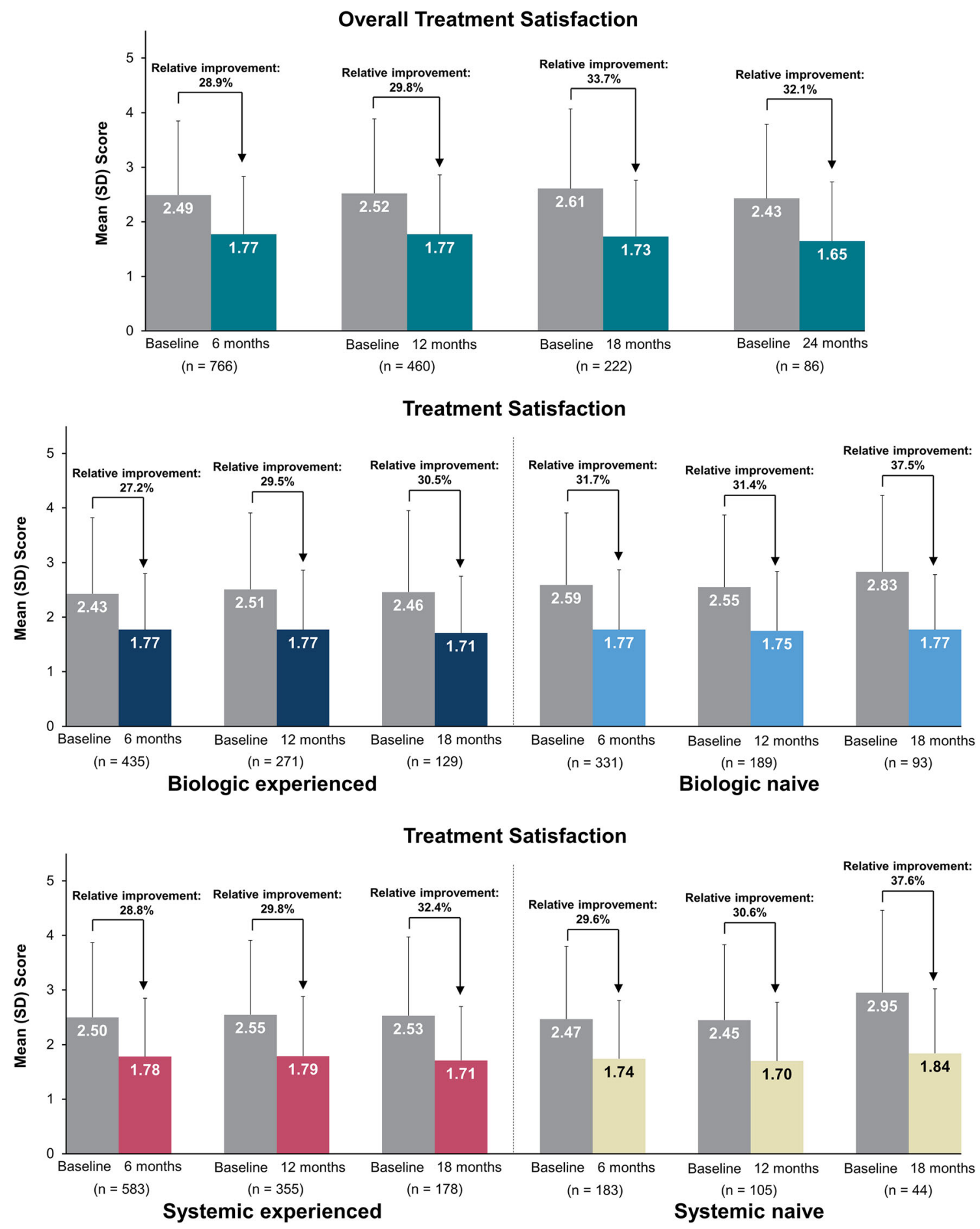
4Fig. 3 Mean treatment satisfaction scores ${ }^{\mathrm{a}}$ at baseline and 6-, 12-, 18-, and 24-month follow-up in all patients who initiated secukinumab and at baseline and 6-, 12-, and 18-month follow-up in those stratified by prior biologic or systemic use $\mathrm{b}^{\mathrm{b}}$.

a Statement: "I believe this treatment is effective in clearing my skin of psoriasis" ( 1 = strongly agree, 2 = somewhat agree, $3=$ neither agree nor disagree, $4=$ somewhat disagree, 5 = strongly disagree). ${ }^{\mathrm{b}}$ Available effectiveness records for treatment satisfaction scores were reported based on the index visit or the visit closest to the index date. Baseline data were from enrolled patients who had 6-, 12-, 18-, and 24-month follow-up periods, respectively
18 months of follow-up for the biologic and systemic subgroups. It is possible that some patients may have had treatment satisfaction, BSA, and PGA $\times$ BSA data at subsequent postindex visits but not the 6-month visit-i.e., the patient cohorts at 12, 18, and 24 months may not be completely derived from the patient cohort at 6 months.

Generalized logistic regression analysis was performed to assess patient demographic (e.g., age, sex, geographic location, comorbidities)

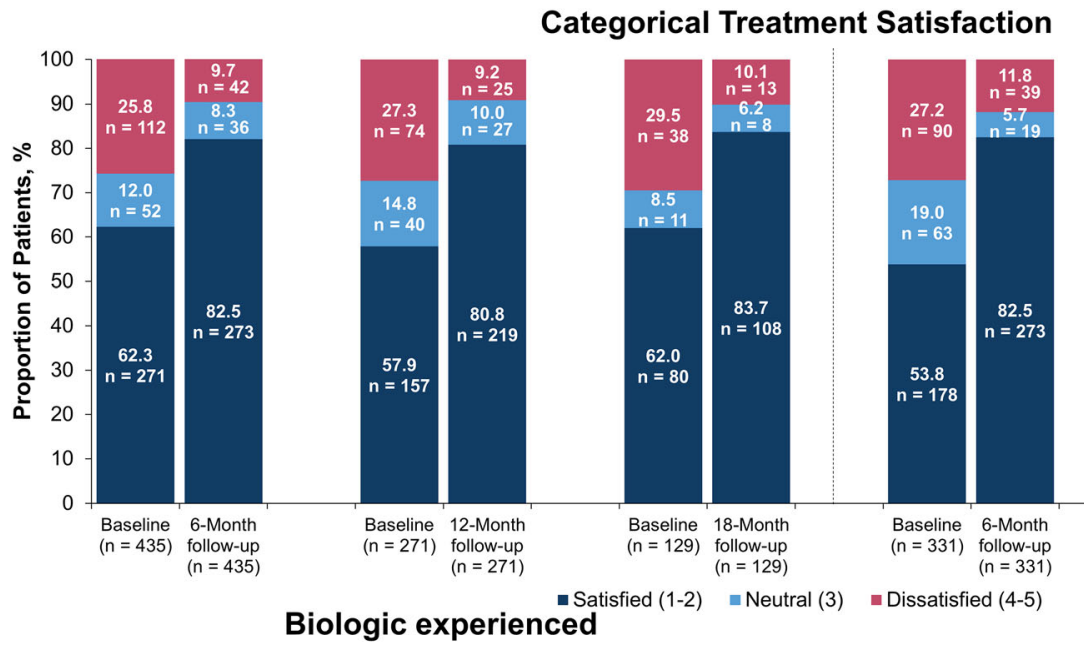

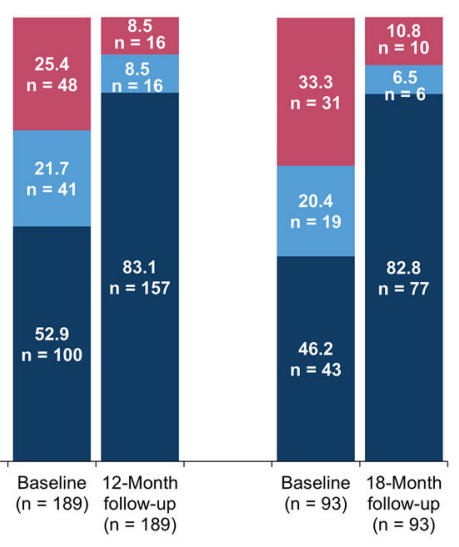

Biologic naive
Categorical Treatment Satisfaction

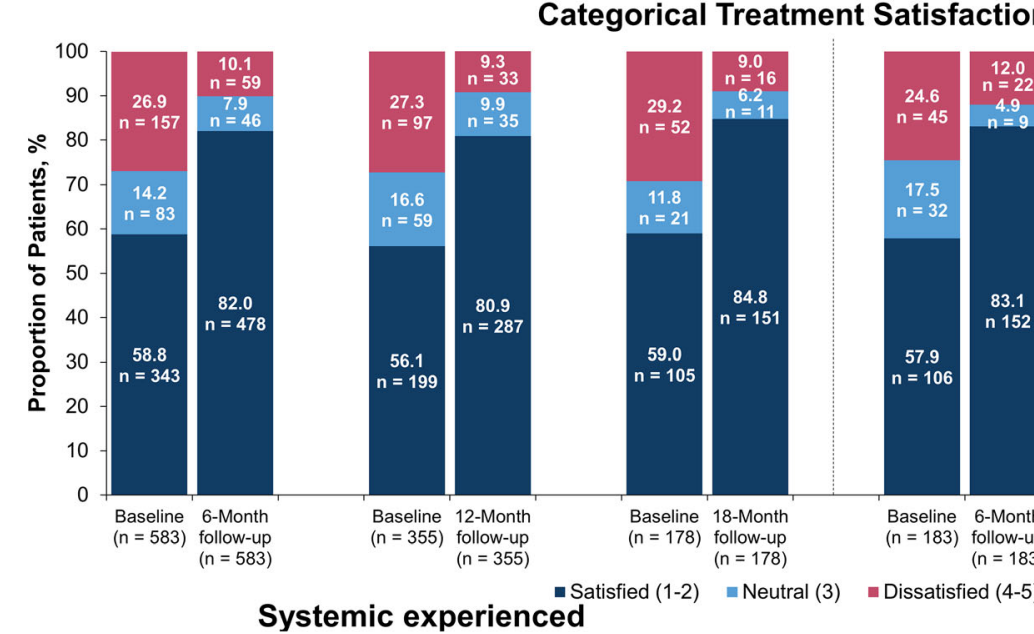

Fig. 4 Categorical change in treatment satisfaction ${ }^{a}$ in patients who initiated secukinumab stratified by prior biologic (top) and systemic (bottom) therapy who had baseline data and 6,12 , and 18 months of follow-up ${ }^{\text {a }}$ 'Statement: "I believe this treatment is effective in clearing my skin of psoriasis ( 1 = strongly agree, 2 = somewhat agree, $3=$ neither agree nor disagree, $4=$ somewhat disagree, $5=$ strongly disagree) .

ed (4-5) Systemic naive

b Available effectiveness records for treatment satisfaction scores were reported based on the index visit or the visit closest to the index date. Baseline data were from enrolled patients who had 6-, 12-, and 18-month follow-up periods, respectively. ${ }^{c}$ Per MMDS masking rules, all counts $<5$ were masked to protect patient identities; therefore, data for "neutral" and "unsatisfied" are not shown 
Table 2 Predictors of treatment satisfaction at 6-month follow-up in patients with psoriasis who initiated secukinumab

\begin{tabular}{|c|c|c|c|}
\hline Category & Characteristic & $\begin{array}{l}\text { Odds } \\
\text { ratio }\end{array}$ & $P$ value \\
\hline Sex (reference: male) & Female & $0.77(0.48,1.24)$ & 0.275 \\
\hline \multirow[t]{5}{*}{ Age group (reference: $18-34$ years) } & $35-44$ years & $1.35(0.56,3.28)$ & 0.508 \\
\hline & $45-54$ years & $0.90(0.41,1.97)$ & 0.784 \\
\hline & $55-64$ years & $0.63(0.28,1.41)$ & 0.264 \\
\hline & $65-74$ years & $1.01(0.40,2.56)$ & 0.976 \\
\hline & $75+$ years & $0.31(0.09,1.06)$ & 0.063 \\
\hline \multirow[t]{3}{*}{ Geographic region (reference: South) } & Northeast & $1.15(0.52,2.57)$ & 0.728 \\
\hline & Midwest & $1.16(0.63,2.12)$ & 0.639 \\
\hline & West & $1.14(0.61,2.12)$ & 0.680 \\
\hline Race (reference: White) & Non-White/unknown & $1.15(0.72,1.85)$ & 0.551 \\
\hline \multirow[t]{2}{*}{ Index year (reference: 2018) } & 2019 & $0.75(0.46,1.22)$ & 0.244 \\
\hline & 2020 & $0.57(0.24,1.40)$ & 0.222 \\
\hline \multirow[t]{7}{*}{ Plaque location } & Hand (includes hand, finger) & $1.01(0.40,2.53)$ & 0.983 \\
\hline & Appendages (includes arm, wrist, leg) & $0.91(0.49,1.69)$ & 0.758 \\
\hline & Foot (includes foot, toe) & $1.16(0.38,3.54)$ & 0.797 \\
\hline & $\begin{array}{l}\text { Trunk (includes trunk, genitalia, and } \\
\text { axillae) }\end{array}$ & $1.23(0.64,2.38)$ & 0.529 \\
\hline & Scalp & $1.09(0.49,2.43)$ & 0.833 \\
\hline & $\begin{array}{l}\text { Head and neck (includes face, } \\
\text { ear, eyelid, nose, lip) }\end{array}$ & $1.28(0.51,3.23)$ & 0.595 \\
\hline & Nail & $0.25(0.04,1.47)$ & 0.124 \\
\hline \multirow[t]{7}{*}{ Comorbidities of interest } & Anxiety/depression & $0.88(0.50,1.54)$ & 0.648 \\
\hline & $\begin{array}{l}\text { Cerebrovascular disease (including } \\
\text { hemorrhagic stroke and transient } \\
\text { ischemic attack/coronary heart disease) }\end{array}$ & $1.28(0.40,4.08)$ & 0.673 \\
\hline & Diabetes & $1.32(0.69,2.54)$ & 0.403 \\
\hline & Hypertension & $1.00(0.59,1.71)$ & 0.999 \\
\hline & Hyperlipidemia & $0.94(0.49,1.81)$ & 0.851 \\
\hline & Psoriatic arthritis & $1.01(0.60,1.68)$ & 0.982 \\
\hline & Malignancies & $0.94(0.45,1.93)$ & 0.856 \\
\hline
\end{tabular}


Table 2 continued

\begin{tabular}{|c|c|c|c|}
\hline Category & Characteristic & $\begin{array}{l}\text { Odds } \\
\text { ratio }\end{array}$ & $P$ value \\
\hline $\begin{array}{l}\text { Early versus late treatment } \\
\text { (reference: early) }\end{array}$ & Late & $1.03(0.58,1.83)$ & 0.920 \\
\hline \multirow{3}{*}{$\begin{array}{l}\text { No. of prior biologics preindex } \\
\text { (reference: } 0 \text { ) }\end{array}$} & 1 & $0.92(0.55,1.55)$ & 0.763 \\
\hline & 2 & $1.37(0.61,3.10)$ & 0.451 \\
\hline & $\geq 3$ & $0.36(0.15,0.87)$ & 0.024 \\
\hline \multirow{4}{*}{$\begin{array}{l}\text { Psoriasis-related therapy used in } \\
12 \text { months preindex not including index } \\
\text { date (reference: no treatment) }\end{array}$} & Other nonbiologic systemic & $1.01(0.56,1.82)$ & 0.982 \\
\hline & Topical therapy & $0.58(0.31,1.09)$ & 0.090 \\
\hline & Phototherapy & $0.59(0.12,2.94)$ & 0.519 \\
\hline & PDE4 inhibitor (apremilast) & $1.30(0.64,2.66)$ & 0.467 \\
\hline \multirow{4}{*}{$\begin{array}{l}\text { Psoriasis-related concomitant therapy } \\
\text { (reference: no treatment) }\end{array}$} & Other nonbiologic systemic & $0.34(0.16,0.70)$ & 0.003 \\
\hline & Topical therapy & $0.95(0.59,1.51)$ & 0.815 \\
\hline & Phototherapy & $3.75(0.28,50.51)$ & 0.319 \\
\hline & PDE4 inhibitor (apremilast) & $0.29(0.08,1.07)$ & 0.064 \\
\hline $\begin{array}{l}\text { Baseline treatment satisfaction } \\
\text { (reference: unsatisfied) }\end{array}$ & Baseline treatment satisfaction & $1.67(1.06,2.62)$ & 0.027 \\
\hline $\begin{array}{l}\text { Time to postindex treatment satisfaction } \\
\text { score used in model (reference: } 5-7 \text { months } \\
\text { postindex) }\end{array}$ & $>7$ months postindex & $0.53(0.19,1.50)$ & 0.233 \\
\hline
\end{tabular}

PDE4 phosphodiesterase-4

and clinical characteristics (e.g., plaque location, baseline treatment satisfaction, and psoriasis-related therapies) that were predictors of treatment satisfaction at $\geq 6$ months after secukinumab initiation, with results reported as odds ratios.

\section{RESULTS}

\section{Patient Demographics and Clinical Characteristics}

In patients who initiated secukinumab and had treatment satisfaction scores at 6 months of follow-up $(N=766)$, the mean (SD) age was 51.8 (14.5) years, and $53.0 \%$ were female (Table 1 ). The most common comorbidities were hypertension, diabetes, anxiety, depression, and hyperlipidemia; psoriatic arthritis was also observed in approximately $25.9 \%$ of patients. Overall, $45.0 \%$ of patients received prior biologic treatment during the 12-month baseline period, the majority of whom previously received either tumor necrosis factor inhibitors or IL-23 inhibitors. Characteristics were generally balanced between biologic-experienced and -naive subgroups as well as systemic-experienced and -naive subgroups.

\section{Change in Treatment Satisfaction from Secukinumab Initiation}

Of 3680 patients with plaque psoriasis in the MMDS database who met the inclusion criteria and were assessed for treatment satisfaction during the baseline period, 766, 460, 222, and 


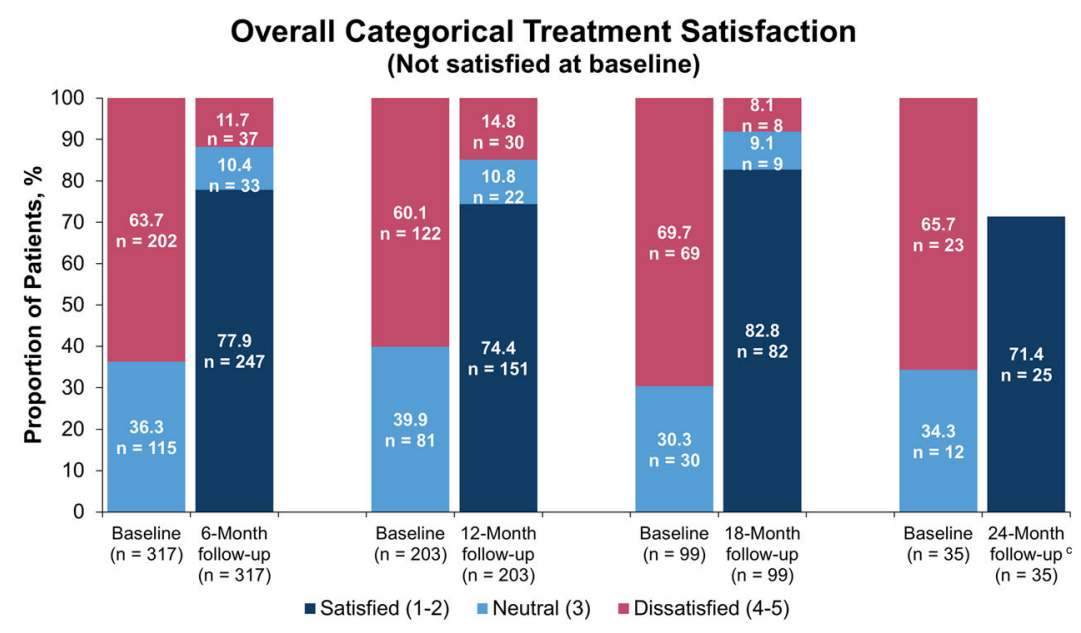

Categorical Treatment Satisfaction

(Not satisfied at baseline)

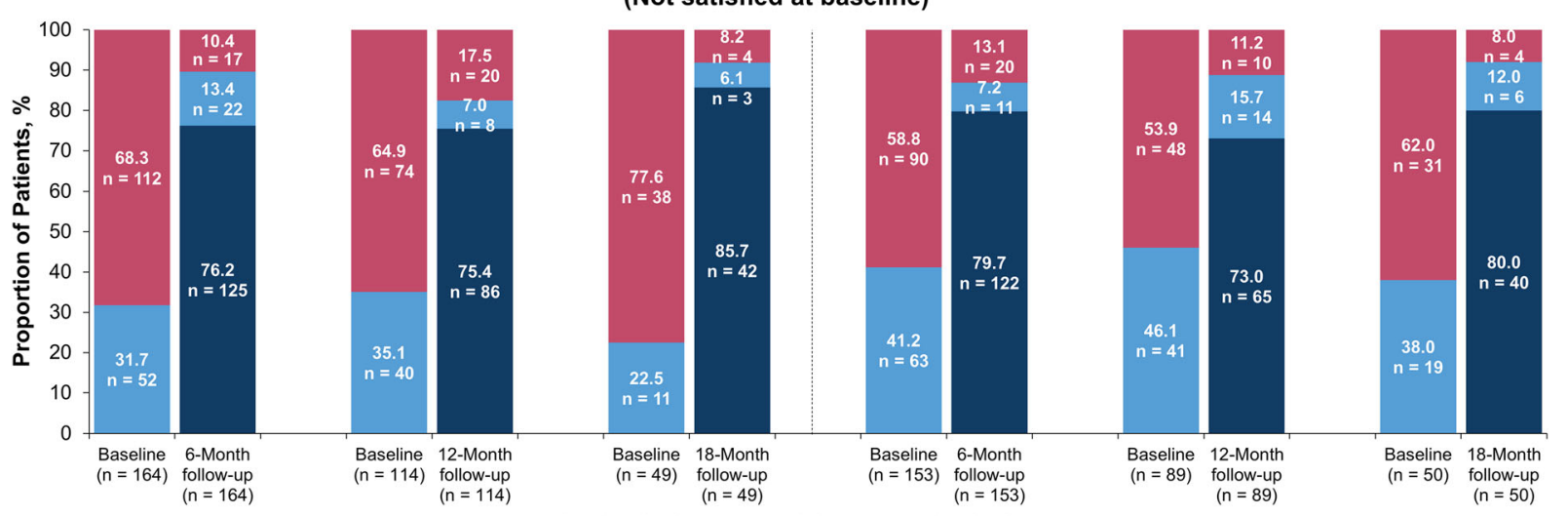

Biologic experienced

Biologic naive

Categorical Treatment Satisfaction

(Not satisfied at baseline)

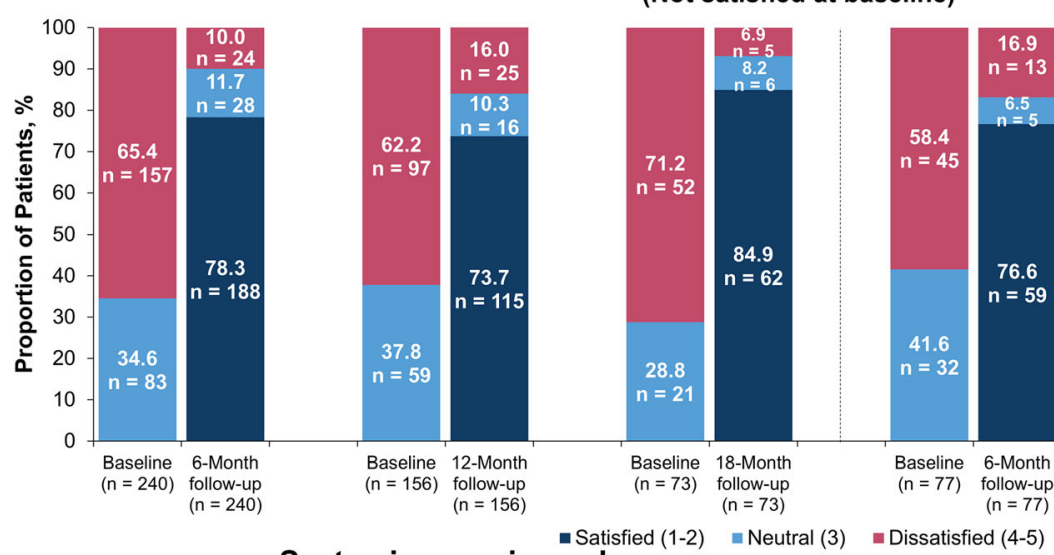

Systemic experienced

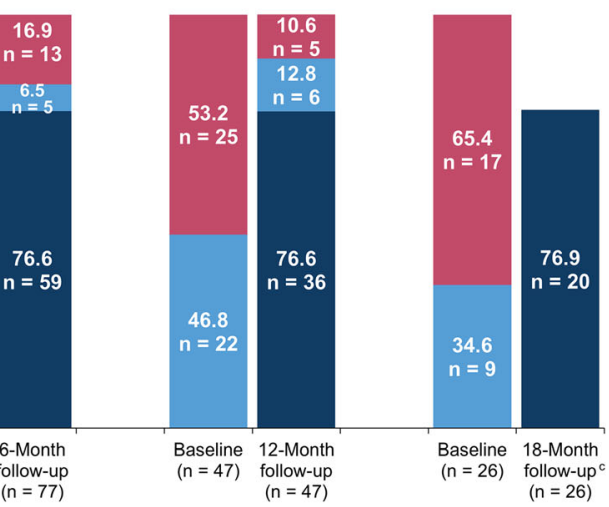

Systemic naive 
4Fig. 5 Categorical change in treatment satisfaction ${ }^{a}$ in the subset of patients who initiated secukinumab with a baseline treatment satisfaction score of 3 , 4 , or 5 at baseline and 6-, 12-, 18-, and 24-month follow-up in all patients who initiated secukinumab; at baseline and 6-, 12-, and 18-month follow-up in those stratified by prior biologic and systemic use ${ }^{\mathrm{b}}$. ${ }^{\mathrm{a}}$ Statement: "I believe this treatment is effective in clearing my skin of psoriasis” ( $1=$ strongly agree, 2 = somewhat agree, $3=$ neither agree nor disagree, $4=$ somewhat disagree, $5=$ strongly disagree). ${ }^{\mathrm{b}}$ Available effectiveness records for treatment satisfaction scores were reported based on the index visit or the visit closest to the index date with a baseline treatment satisfaction score of 3 , 4 , or 5 during the 12-month baseline period. Baseline data were from enrolled patients who had 6-, 12-, 18-, and 24-month follow-up periods, respectively. ${ }^{c}$ Per MMDS masking rules, all counts $<5$ were masked to protect patient identities; therefore, data for "neutral" and "unsatisfied" are not shown

86 patients, respectively, had additional treatment satisfaction scores through $6,12,18$, and 24 months.

In all patients who initiated secukinumab with additional treatment satisfaction scores at $6,12,18$, and 24 months of follow-up, 58.6\%, $55.9 \%, 55.4 \%$, and $59.3 \%$ of patients, respectively, were satisfied with their prior treatment at baseline. The proportion of patients who strongly or somewhat agreed that secukinumab was effective in clearing their skin of psoriasis at $6,12,18$, and 24 months, respectively, was $82.3 \%$ (absolute change from baseline, 23.6\%), $81.7 \%$ (25.9\%), $83.3 \%$ (27.9\%), and $81.4 \%$ (22.1\%) (Fig. 2). The overall mean (SD) treatment satisfaction score improved from 2.49 (1.36) at baseline to 1.77 (1.06) at 6 months, and comparable improvements in satisfaction scores were reported at each follow-up period up through 24 months (Fig. 3).

Biologic- and systemic-naive patients reported less satisfaction with prior treatment compared with biologic- and systemic-experienced patients at baseline. However, similar proportions of patients were satisfied with treatment following secukinumab initiation irrespective of prior treatment, and enhanced satisfaction was maintained up to 18 months (Fig. 4). Further, when taking into account absolute change in satisfaction, treatment-naive patients had greater improvement from baseline than treatment-experienced patients (Fig. S1 in Supplementary Material).

Predictors of treatment satisfaction at 6 months of follow-up were use of $\geq 3$ prior biologics, use of concomitant other psoriasisrelated nonbiologic systemic therapy, and baseline satisfaction with treatment (Table 2).

\section{Improvements in Treatment Satisfaction in Patients Unsatisfied at Initiation}

A total of $317,203,99$, and 35 patients who reported a treatment assessment score of 3, 4, or 5 at baseline (i.e., unsatisfied with prior treatment), respectively, had follow-up treatment satisfaction scores through $6,12,18$, and 24 months. The majority of these patients were satisfied with the effectiveness of secukinumab in clearing their skin of psoriasis at each followup, with $77.9 \%, 74.4 \%, 82.8 \%$, and $71.4 \%$ of patients satisfied with treatment at $6,12,18$, and 24 months, respectively (Fig. 5). The total mean (SD) treatment satisfaction score was 3.92 (0.80) at baseline and 1.87 (1.11) at 6 months, with similar improvements in satisfaction scores maintained through 24 months (Fig. 6).

\section{Change in Clinical Effectiveness Outcomes from Secukinumab Initiation}

In patients with plaque psoriasis in the MMDS database who initiated secukinumab and had baseline BSA values ( $n=3174), 2583,1657,830$, and 331 patients, respectively, had BSA values at $6,12,18$, and 24 months. Of patients who had baseline PGA $\times$ BSA scores $(n=1676), 1326$, 841,423 , and 170 patients, respectively, had PGA $\times$ BSA scores at $6,12,18$, and 24 months. The median BSA score in all patients decreased from 10.0 at baseline to 3.0 at 6 months and was maintained up to 18 months; median BSA score was further reduced to 2.0 at 24 months (Fig. S2 in Supplementary Material). The median PGA $\times$ BSA score decreased from 30.0 at baseline to 4.0 at 6 months, which was maintained through the duration of follow-up, decreasing from 30.0 at baseline to 3.0 at 24 months 

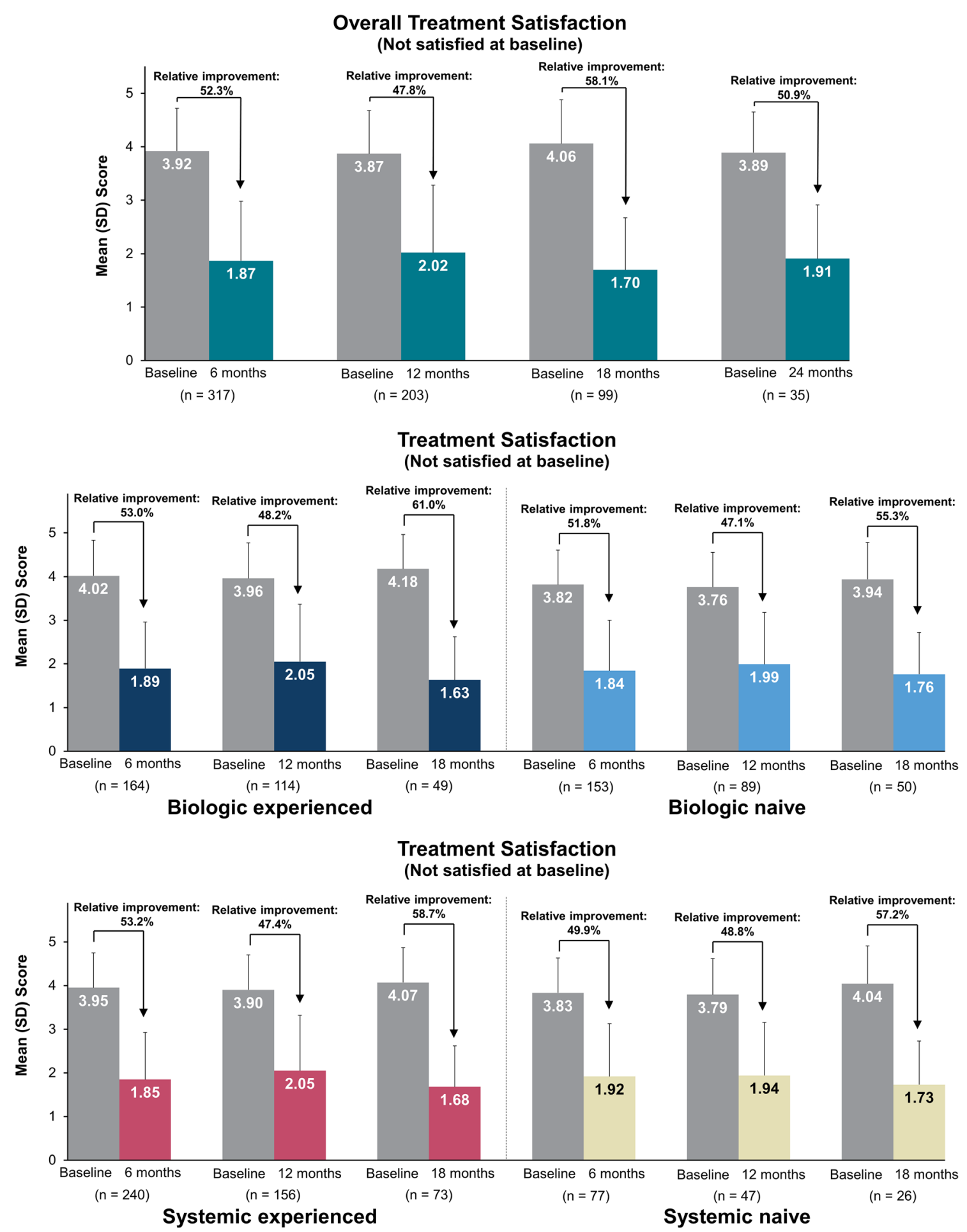
4Fig. 6 Mean change in treatment satisfaction ${ }^{a}$ in the subset of patients who initiated secukinumab with a baseline treatment satisfaction score of 3 , 4 , or 5 at baseline and 6-, 12-, 18-, and 24-month follow-up in all patients who initiated secukinumab; at baseline and 6-, 12-, and 18-month follow-up in those stratified by prior biologic and systemic use ${ }^{\mathrm{b}}$. ${ }^{\mathrm{a}}$ Statement: "I believe this treatment is effective in clearing my skin of psoriasis” ( $1=$ strongly agree, 2 = somewhat agree, $3=$ neither agree nor disagree, $4=$ somewhat disagree, $5=$ strongly disagree). ${ }^{\mathrm{b}}$ Available effectiveness records for treatment satisfaction scores were reported based on the index visit or the visit closest to the index date with a baseline treatment satisfaction score of 3 , 4 , or 5 during the 12-month baseline period. Baseline data were from enrolled patients who had 6-, 12-, 18-, and 24-month follow-up periods, respectively

(Fig. S3 in Supplementary Material). Similar reductions from baseline in BSA and PGA $\times$ BSA scores were observed at each follow-up period, regardless of prior treatment experience.

\section{DISCUSSION}

In this real-world analysis, all patients achieved and sustained a high level of treatment satisfaction (80-85\%) with secukinumab over 24 months of follow-up, regardless of their prior treatment. Over the 24-month follow-up period, there was a growing or stable trend for improvement in treatment satisfaction. Furthermore, treatment-naive patients showed greater improvement in satisfaction compared with treatment-experienced patients, as they were more dissatisfied with their conventional treatment at baseline. Among the subset of patients who were unsatisfied with prior treatment at baseline, approximately $75 \%$ of patients achieved satisfaction with secukinumab treatment through 24 months. Additionally, predictors of treatment satisfaction post 6 months of follow-up were use of $\geq 3$ prior biologics and use of concomitant psoriasis-related other systemic therapies. These results highlight the need for early intervention with more advanced biologic treatments, such as secukinumab.
These results are similar to those of previous studies. In the PROSE study, complete qualityof-life normalization was observed at week 16 and sustained through week 52 with secukinumab treatment, regardless of prior treatment history [21]. Furthermore, patients who were biologic naive had a slightly higher mean score on the Treatment Satisfaction Questionnaire for Medication compared with those previously exposed to biologics, indicating better perception of treatment effect [21]. Additionally, survey studies in Canada and Italy have shown that treatment with both biologic and nonbiologic systemic therapies leads to high treatment satisfaction, with higher satisfaction achieved using biologics than nonbiologic systemic therapies $[22,23]$. These findings support the observations from our study that patients may benefit and be highly satisfied with biologic therapy, with the investigators suggesting that greater efforts are needed to improve communication between physicians and patients to provide enough information about biologic therapies to make informed decisions on their use [22, 23].

Patient satisfaction is a key component to evaluating a patient's overall experience with a treatment. In a US real-world study, patients who were dissatisfied with their treatment were more likely to have more severe overall disease activity and psoriasis symptoms (pain, itching, and scaling) compared with those who were satisfied [24]. Patient satisfaction with treatment is driven by a variety of factors such as speed of improvement, symptom alleviation, treatment history, and quality-of-life improvement, with patients placing importance of some factors over others $[25,26]$. Of note, patients can achieve improvement in overall skin clearance but still be dissatisfied with their treatment, possibly due to continued impact of disease on challenging-to-treat areas (e.g., nails, scalp, and genitals). Therefore, it is important to assess clinical outcomes by measuring skin clearance along with treatment satisfaction to allow for a comprehensive evaluation of treatment effectiveness. This study provides evidence of the long-term real-world treatment satisfaction with effectiveness of secukinumab regardless of prior treatment experience. 
The burden of illness associated with psoriasis negatively impacts patient quality of life, leading to substantial economic, psychological, and social burdens. Physicians should aim to achieve minimal disease activity to minimize the impact of psoriasis on patients. The National Psoriasis Foundation recommends an initial psoriasis treat-to-target goal of reducing affected BSA to $\leq 1 \%$ after 3 months, with a reduction to $\leq 3 \%$ considered an acceptable response [27]. In clinical trials, patients treated with biologic therapies have demonstrated skin clearance through achievement of Psoriasis Area and Severity Index 90 or 100 responses; however, achievement of affected BSA $<3 \%$ and PGA score of $0 / 1$ are the mainstay routine criteria for skin clearance in US clinical practice. Real-world studies are needed to assess the effectiveness of biologic therapies within the general population of patients with psoriasis, most of whom tend to be biologic experienced [18]. Patients who are biologic experienced tend to have worse disease severity $[17,28]$ and are more likely to have had inadequate treatment responses [29, 30]. Although Canadian [31], German [32], Japanese [33], and meta-analysis [34] studies have reported comparable effectiveness of secukinumab in patients with psoriasis between clinical trial and real-world data, there remains a lack of real-world studies in the USA. Data from the US CorEvitas (formerly Corrona) Psoriasis Registry showed that, in 118 patients with moderate-to-severe psoriasis who were treated with secukinumab and maintained treatment at 6 months, the mean affected BSA decreased from $16.7 \%$ at baseline to $4.6 \%$ at 6 months, while the proportion of patients who achieved an Investigator's Global Assessment of $0 / 1$ increased from $5.9 \%$ at baseline to $50.0 \%$ at 6 months [18]. Patients are required to be on biologics to be enrolled in the CorEvitas Psoriasis Registry, and are therefore more advanced relative to those in the MMDS database, which may contribute to some of the differences in responses; however, our findings provide additional data to support the effectiveness of secukinumab in US real-world settings.

Of note, the MMDS database is drawn from the EMA EMR and includes data captured only from physicians contributing to the EMR network, which may limit the information they provide; these data were also limited to dermatology EMRs and did not include patients who may have switched to providers using a different EMR system. As such, results may not be generalizable to all patients with psoriasis. Also, the prescriptions observed in the EMR system are orders; whether or not the patient actually filled the prescription, and the actual duration of therapy, cannot be confirmed. No continuous health plan enrollment information was captured in EMA. In addition, the sample size decreased significantly from 6 to 18 months of follow-up, and those patients who may have been unsatisfied may have dropped out of the EMR system, potentially causing a survival bias in this as-observed analysis. Finally, this study was retrospective in nature and relied on coding to make associations between secukinumab exposure and effectiveness outcomes.

In this analysis of deidentified EMR data from patients with predominantly moderate-tosevere plaque psoriasis, patients achieved and maintained a high level of treatment satisfaction with secukinumab up to 24 months, regardless of previous treatment experience. Treatment satisfaction improvement was increased or maintained over 24 months of follow-up for all patient subgroups, including in the subset of patients who were unsatisfied with prior treatment at baseline. Even though treatment-naive patients were less satisfied at baseline, they achieved the same level of satisfaction as treatment-experienced patients. These findings support data from randomized controlled trials and highlight the sustained real-world satisfaction with secukinumab in clearing the skin of psoriasis. Further research is needed to supplement current findings and assess additional determinants of treatment satisfaction beyond achievement of clear skin, with complete data on confirmed filled prescription of biologics and consistent effectiveness measures over an extended time period. 


\section{ACKNOWLEDGEMENTS}

Funding. This study was sponsored by Novartis Pharmaceuticals Corporation, East Hanover, NJ. Support for third-party writing assistance and the Journal's Rapid Serve Fee were funded by Novartis Pharmaceuticals Corporation, East Hanover, NJ.

Authorship. All named authors meet the International Committee of Medical Journal Editors (ICMJE) criteria for authorship for this article, take responsibility for the integrity of the work as a whole, and have given their approval for this version to be published.

Medical Writing, Editorial, and Other Assistance. Support for third-party writing assistance for this manuscript, furnished by Meaghan Paganelli, PhD, and Eric Deutsch, $\mathrm{PhD}$, CMPP, of Health Interactions, Inc, was provided by Novartis Pharmaceuticals Corporation, East Hanover, NJ.

Disclosures. April W. Armstrong has served as an investigator or consultant for AbbVie, Bristol Myers Squibb, Dermavant, Dermira, Eli Lilly, Janssen, LEO Pharma, Modernizing Medicine, Novartis, Ortho Dermatologics, Regeneron, Sanofi Genzyme, Science 37, and UCB. Catherine B. McGuiness, Xin Wang, Yi Wang, and Chi-Chang Chen are employees of IQVIA who received consulting fees to conduct this research. Dhaval Patil, Eugenia Levi, and Elizabeth Nguyen are employees of Novartis Pharmaceuticals Corporation. Paul S. Yamauchi has served as an investigator for Amgen, Celgene, Dermira, Galderma, Janssen, LEO Pharma, Eli Lilly, MedImmune, Novartis, Pfizer, Regeneron, and Sandoz and has served as an advisor and/or speaker for AbbVie, Amgen, Baxter, Celgene, Dermira, Galderma, Janssen, LEO Pharma, Eli Lilly, Novartis, Pfizer, and Regeneron.

Data Availability. All data generated or analyzed during this study are included in this published article.
Compliance with Ethics Guidelines. Data in the Modernizing Medicine EMR database are deidentified in compliance with HIPAA regulations and were made available to all authors. This study was exempt from IRB review as it did not involve the collection, use, or transmittal of individually identifiable data.

Open Access. This article is licensed under a Creative Commons Attribution-NonCommercial 4.0 International License, which permits any non-commercial use, sharing, adaptation, distribution and reproduction in any medium or format, as long as you give appropriate credit to the original author(s) and the source, provide a link to the Creative Commons licence, and indicate if changes were made. The images or other third party material in this article are included in the article's Creative Commons licence, unless indicated otherwise in a credit line to the material. If material is not included in the article's Creative Commons licence and your intended use is not permitted by statutory regulation or exceeds the permitted use, you will need to obtain permission directly from the copyright holder. To view a copy of this licence, visit http://creativecommons.org/licenses/by$\mathrm{nc} / 4.0 /$.

\section{REFERENCES}

1. Rachakonda TD, Schupp CW, Armstrong AW. Psoriasis prevalence among adults in the United States. J Am Acad Dermatol. 2014;70(3):512-6. https://doi. org/10.1016/j.jaad.2013.11.013.

2. Gottlieb A, Korman NJ, Gordon KB, et al. Guidelines of care for the management of psoriasis and psoriatic arthritis: section 2. Psoriatic arthritis: overview and guidelines of care for treatment with an emphasis on the biologics. J Am Acad Dermatol. 2008;58(5):851-64. https://doi.org/10.1016/j.jaad. 2008.02.040.

3. Palfreeman AC, McNamee KE, McCann FE. New developments in the management of psoriasis and psoriatic arthritis: a focus on apremilast. Drug Des Devel Ther. 2013;7:201-10. https://doi.org/10. 2147/DDDT.S32713. 
4. Gottlieb AB, Dann F. Comorbidities in patients with psoriasis. Am J Med. 2009;122(12):1150.e1-9. https://doi.org/10.1016/j.amjmed.2009.06.021.

5. Schaefer CP, Cappelleri JC, Cheng R, et al. Health care resource use, productivity, and costs among patients with moderate to severe plaque psoriasis in the United States. J Am Acad Dermatol. 2015;73(4): 585-93.e3. https://doi.org/10.1016/j.jaad.2015.06. 049 .

6. Poulin Y, Sheth P, Gu Y, Teixeira HD. Health-related quality of life worsens disproportionately to objective signs of psoriasis after withdrawal of adalimumab therapy. Dermatol Ther (Heildelb). 2014;4(1):33-42. https://doi.org/10.1007/s13555014-0043-4.

7. Brezinski EA, Dhillon JS, Armstrong AW. Economic burden of psoriasis in the United States: a systematic review. JAMA Dermatol. 2015;151(6):651-8. https://doi.org/10.1001/jamadermatol.2014.3593.

8. Horn EJ, Fox KM, Patel V, Chiou CF, Dann F, Lebwohl M. Association of patient-reported psoriasis severity with income and employment. J Am Acad Dermatol. 2007;57(6):963-71. https://doi.org/10. 1016/j.jaad.2007.07.023.

9. Menter A, Strober BE, Kaplan DH, et al. Joint AADNPF guidelines of care for the management and treatment of psoriasis with biologics. J Am Acad Dermatol. 2019;80(4):1029-72. https://doi.org/10. 1016/j.jaad.2018.11.05.7.

10. Blauvelt A, Prinz JC, Gottlieb AB, et al. Secukinumab administration by pre-filled syringe: efficacy, safety and usability results from a randomized controlled trial in psoriasis (FEATURE). Br J Dermatol. 2015;172(2):484-93. https://doi.org/10. 1111/bjd.13348.

11. Langley RG, Elewski BE, Lebwohl M, et al. Secukinumab in plaque psoriasis-results of two phase 3 trials. N Engl J Med. 2014;371(4):326-38. https:// doi.org/10.1056/NEJMoa1314258.

12. Paul C, Lacour JP, Tedremets L, et al. Efficacy, safety and usability of secukinumab administration by autoinjector/pen in psoriasis: a randomized, controlled trial (JUNCTURE). J Eur Acad Dermatol Venereol. 2015;29(6):1082-90. https://doi.org/10. $1111 / j d v .12751$.

13. Armstrong AW, Vender R, Kircik L. Secukinumab in the treatment of palmoplantar, nail, scalp, and pustular psoriasis. J Clin Aesthet Dermatol. 2016;9(6 Suppl 1):S12-6.

14. Mease P, McInnes IB. Secukinumab: a new treatment option for psoriatic arthritis. Rheumatol Ther.
2016;3(1):5-29. https://doi.org/10.1007/s40744016-0031-5.

15. Thaci D, Blauvelt A, Reich K, et al. Secukinumab is superior to ustekinumab in clearing skin of subjects with moderate to severe plaque psoriasis: CLEAR, a randomized controlled trial. J Am Acad Dermatol. 2015;73(3):400-9. https://doi.org/10.1016/j.jaad. 2015.05.013.

16. Bissonnette R, Luger $\mathrm{T}$, Thaci $\mathrm{D}$, et al. Secukinumab demonstrates high sustained efficacy and a favourable safety profile in patients with moderate-tosevere psoriasis through 5 years of treatment (SCULPTURE Extension Study). J Eur Acad Dermatol Venereol. 2018;32(9):1507-14. https://doi.org/ $10.1111 / j d v .14878$.

17. Strober B, Karki C, Mason M, et al. Characterization of disease burden, comorbidities, and treatment use in a large, US-based cohort: results from the Corrona Psoriasis Registry. J Am Acad Dermatol. 2018;78(2):323-32. https://doi.org/10.1016/j.jaad. 2017.10.012.

18. Strober BE, Germino R, Guana A, et al. US realworld effectiveness of secukinumab for the treatment of psoriasis: 6-month analysis from the Corrona Psoriasis Registry. J Dermatolog Treat. 2020;31(4):333-41. https://doi.org/10.1080/ 09546634.2019 .1603361$.

19. Pariser D, Frankel E, Schlessinger J, et al. Efficacy of secukinumab in the treatment of moderate to severe plaque psoriasis in the North American subgroup of patients: pooled analysis of four phase 3 studies. Dermatol Ther (Heidelb). 2018;8(1):17-32. https://doi.org/10.1007/s13555-017-0211-4.

20. Walsh JA, McFadden M, Woodcock J, et al. Product of the physician global assessment and body surface area: a simple static measure of psoriasis severity in a longitudinal cohort. J Am Acad Dermatol. 2013;69(6):931-7. https://doi.org/10.1016/j.jaad. 2013.07.040.

21. Augustin M, Dauden E, Mrowietz U, et al. Secukinumab treatment leads to normalization of quality of life and disease symptoms in psoriasis patients with or without prior systemic psoriasis therapy: the PROSE study results. J Eur Acad Dermatol Venereol. 2021;35(2):431-40. https://doi.org/10. $1111 /$ jdv.16632.

22. Ighani A, Yu AM, Sandhu VK, Barankin B, Manolson MF. Satisfaction and awareness of systemic psoriasis treatments: a national survey comparing biologic and nonbiologic users. J Cutan Med Surg. 2019;23(2):148-56. 1203475418808764 . 
23. Esposito M, Giunta A, Gisondi P, et al. Satisfaction and attitudes toward systemic treatments for psoriasis: a cross-sectional study. Dermatol Ther. 2021;34(3):e14949. https://doi.org/10.1111/dth.149 49.

24. Korman NJ, Zhao Y, Pike J, Roberts J, Sullivan E, Kemhus M. Satisfaction with current psoriasis treatment: misalignment between physician and patient perceptions. Dermatol Online J. 2016;22(7): 13030/qt7405k1nn.

25. Boeri M, Saure D, Schuster C, et al. Impact of clinical and demographic characteristics on patient preferences for psoriasis treatment features: results from a discrete-choice experiment in a multicountry study. J Dermatolog Treat. 2021; https://doi. org/10.1080/09546634.2020.1869145.

26. Feldman S, Poulos C, Giloteau I, et al. Exploring patient preferences for the treatment of moderate to severe psoriasis: a discrete-choice experiment study in the US. Poster presented at: 27th European Academy of Dermatology and Venereology Congress; September 12-16, 2018; Paris, France.

27. Armstrong AW, Siegel MP, Bagel J, et al. From the Medical Board of the National Psoriasis Foundation: treatment targets for plaque psoriasis. J Am Acad Dermatol. 2017;76(2):290-8. https://doi.org/10. 1016/j.jaad.2016.10.017.

28. Strober B, Greenberg JD, Karki C, et al. Impact of psoriasis severity on patient-reported clinical symptoms, health-related quality of life and work productivity among US patients: real-world data from the Corrona Psoriasis Registry. BMJ Open. 2019;9(4):e027535. https://doi.org/10.1136/ bmjopen-2018-027535.

29. Iskandar IYK, Warren RB, Lunt M, et al. Differential drug survival of second-line biologic therapies in patients with psoriasis: observational cohort study from the British Association of Dermatologists Biologic Interventions Register (BADBIR). J Invest Dermatol. 2018;138(4):775-84. https://doi.org/10. 1016/j.jid.2017.09.044.

30. Menter A, Papp KA, Gooderham M, et al. Drug survival of biologic therapy in a large, disease-based registry of patients with psoriasis: results from the Psoriasis Longitudinal Assessment and Registry (PSOLAR). J Eur Acad Dermatol Venereol. 2016;30(7):1148-58. https://doi.org/10.1111/jdv. 13611.

31. Georgakopoulos JR, Ighani A, Zhou LL, Yeung J. Efficacy and safety of secukinumab in treating moderate to severe plaque psoriasis in two realworld Canadian dermatology clinics: a multicenter retrospective study. J Eur Acad Dermatol Venereol. 2018;32(1):e32-4. https://doi.org/10.1111/jdv. 14468.

32. Korber A, Thaci D, von Kiedrowski R, et al. Secukinumab treatment of moderate to severe plaque psoriasis in routine clinical care: real-life data of prior and concomitant use of psoriasis treatments from the PROSPECT study. J Eur Acad Dermatol Venereol. 2018;32(3):411-9. https://doi.org/10. $1111 / j d v .14604$.

33. Momose M, Asahina A, Umezawa $Y$, Nakagawa $H$. Long-term clinical efficacy and safety of secukinumab for Japanese patients with psoriasis: a single-center experience. J Dermatol. 2018;45(3): 318-21. https://doi.org/10.1111/1346-8138.14145.

34. Augustin M, Jullien D, Martin A, Peralta C. Realworld evidence of secukinumab in psoriasis treatment-a meta-analysis of 43 studies. J Eur Acad Dermatol Venereol. 2020;34(6):1174-85. https:// doi.org/10.1111/jdv.16180. 